\title{
Relationship between the professional of reference and the permanence of ADHD patients in a psychosocial care center for children and adolescents in Minas Gerais
}

Relação entre o profissional de referência e a permanência de pacientes com TDAH em um centro de atenção psicossocial para crianças e adolescentes em Minas Gerais

Lucas Araujo Guedes', Wendel Coura Vital2, Christine Vianna Algarves Magalhães³, Carla Penido Serra4, Vanja Maria Veloso ${ }^{4}$

\section{DEAR EDITOR,}

Attention deficit hyperactivity disorder (ADHD) is a common neurodevelopmental disorder in childhood. It is characterized by a persistent pattern of inattention associated or not with hyperactivity and impulsivity, which are noted in at least two contexts, including home and school'. According to Rohde et al. ${ }^{2}$, ADHD affects 3\%-6\% of Brazilian school-age children.

The literature suggests that pharmacotherapy is the most effective form of treatment of children and adolescents with $\mathrm{ADHD}^{3}$. However, since ADHD is a complex disorder that affects many different areas of performance ${ }^{4}$, the treatment frequently involves a complex approach, including both psychosocial and psychopharmacological interventions ${ }^{5}$.

To evaluate the relationship between the type of professional treating the ADHD patient and the patients' adherence to treatment, a cross-sectional study was performed using data from the records of all ADHD patients who sought treatment in a Psychosocial Care Center for Children and Adolescent (PCCCA) located in the state of Minas Gerais since its creation until 31 December 2012.

A total of 154 records of patients diagnosed with ADHD were reviewed and divided into two groups: group 1 included patients who were not taking any medication and group 2 included patients who were taking psychotropic drugs. In group 1, 75.86\% were males, while in group 2, males represented $77.60 \%$ of the sample. The majority of individuals in group 1 (75.86\%) had between 5 and 14 year-old, while $84.80 \%$ of individuals in group 2 belonged to this age group. As can be seen, these different were not statistically different.

An important characteristic of the pharmacotherapy prescribed in PCCCA healthcare units is that most patients who receive drug therapy for ADHD (67.20\%) are being treated with tricyclic antidepressants instead of methylphenidate. When patients are treated without psychoactive drugs, the main approach is the psychosocial.

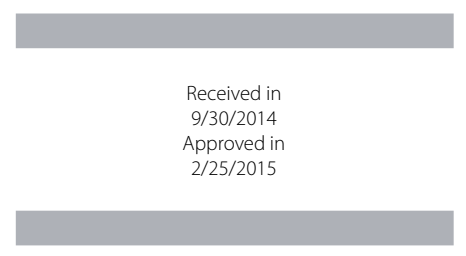

DOI: $10.1590 / 0047-2085000000062$

\footnotetext{
1 Universidade Federal de Ouro Preto (UFOP), Escola de Farmácia, Programa de Pós-graduação em Ciências Farmacêuticas. 2 UFOP, Escola de Farmácia, Laboratório de Pesquisas Clínicas.

3 Centro de Atenção Psicossocial Infanto-juvenil de Ouro Preto. 4 UFOP, Escola de Farmácia, Departamento de Farmácia.
}

Correspondence address to: Lucas Araujo Guedes Rua das Graúnas, 2, ap. 502, Renascença II 650075-190 - São Luís, MA, Brazil

Email: lucas.araujoguedes@gmail.com 
We found a significant association between the type of treatment being administered and the patients adherence to treatment provided, i.e. while only $37.93 \%$ of patients in group 1 (in which treatment was more frequently provided by psychologists) remained in service, up to $61.60 \%$ in group 2 (in which treatment was most frequently provided by psychiatrists) remained under treatment $(p<0.05)$.

We speculate that the group that received medication was the one that showed the greatest levels of satisfaction and improvement in ADHD symptoms, so remaining in treatment in PCCCA. Alternatively, the high rate of adherence to treatment in group 2 may also be related to need for medical monitoring and to obtain prescriptions, which also explains the fact that the doctors are the professional responsible for $96 \%$ of these patients. As the patients in group 1 did not require access to the medicines, they were not subject to frequent medical visits. In the latter case, the psychologist was the leading professional responsible for monitoring the patient (79.31\%).
With these results we can say that the need to obtain medical consultation and prescription to purchase the drug is an essential factor for the stay of patients in a health care facility.

\section{REFERENCES}

1. Smoot $L C$, Boothby $L A$, Gillett RC. Clinical assessment and treatment of $A D H D$ in children. Int J Clin Pract. 2007;61(10):1730-8.

2. Rohde LA, Szobot C, Polanczyk G, Schmitz M, Martins S, Tramontina S. Attention-deficit/ hyperactivity disorder in a diverse culture: do research and clinical findings support the notion of a cultural construct for the disorder? Biol Psychiatr. 2005;57(11):1436-41.

3. Condemarín M, Gorostegui ME, Milicic N. Transtorno do déficit de atenção: estratégias para o diagnóstico e a intervenção psicoeducativa. Tradução de Magda Lopes. São Paulo: Editora Planeta do Brasil; 2006.

4. Stubbe D. Transtornos de excreção: encoprese funcional e enurese funcional. In: Stubbe D. Psiquiatria da infância e adolescência. Porto Alegre: Artmed; 2008.

5. Rohde LA, Biederman J, Zimmermann H, Schmitz M, Martins S, Tramontina S. Exploring ADHD Age-of-onset criterion in Brazilian adolescents. Eur Child Adolesc Psychiatry. 2000;9(3):212-8. 